\title{
Effect of elementary Se and Te on the sign of the temperature coefficient of electroconductivity of metallic $\mathrm{Sb}$ and $\mathrm{Bi}$
}

\author{
Oleg N. MUSTIATSA ${ }^{1}$, Vladimir I. LYSIN ${ }^{2}$, Irene V. KOVALENKO \\ ${ }^{1}$ Department of Road-Building Materials and Chemistry, National Transport University, \\ Suvorova St. 1, 01010 Kyiv, Ukraine \\ ${ }^{2}$ Department of General and Inorganic Chemistry, National Technical University of Ukraine "KPI”, \\ Prosp. Peremogy 37, 03056 Kyiv, Ukraine \\ * Corresponding author: Tel.: +380 44 4068210; e-mail: dana_ecology@ukr.net
}

Received May 27, 2015; accepted June 24, 2015; available on-line September 1, 2015

The effect of Se and Te additions on the electroconductivity of molten $\mathrm{Sb}$ and Bi was investigated. The compositions of the systems metal ( $\mathrm{Sb}, \mathrm{Bi}$ ) - chalcogen ( $\mathrm{Se}, \mathrm{Te}$ ), where sign inversion of the temperature coefficient of electroconductivity takes place, were determined. Changes of the values and character of the conductivity in the investigated systems are explained by chemical interaction of the components and by modification of the chemical bonds from metallic (for Sb and Bi) to covalent, characteristic of chalcogenides.

Electroconductivity / Temperature coefficient / Melts

\section{Introduction}

It is well known that the temperature dependence of the electroconductivity of metals is characterized by a negative temperature coefficient. From scientific and practical viewpoints it is interesting to determine the concentration correlation metal-chalcogen where the electroconductivity of a chemical system changes its temperature dependence.

Melts of the systems $\mathrm{Sb}-\mathrm{Se}, \mathrm{Sb}-\mathrm{Te}, \mathrm{Bi}-\mathrm{Se}$, and $\mathrm{Bi}-\mathrm{Te}$ were investigated in a wide temperature interval to determine the concentration limits of the effect of the chalcogens (Se, Te) on the properties of natural metals $(\mathrm{Sb}, \mathrm{Bi})$, namely the temperature dependence of electroconductivity.

\section{Experimental}

The samples were prepared by direct fusion with periodic mixing of appropriate quantities of metal and chalcogen, in quartz test tubes with an inert atmosphere of $\mathrm{Ar}$, at temperatures $50^{\circ} \mathrm{C}$ higher than the melting point of the metal. After synthesis the samples were analyzed by methods described in [1-3].

The electroconductivity of metallic $\mathrm{Sb}$ and $\mathrm{Bi}$ was investigated by the contact method in a quartz cell with a constant not lower than $10^{3} \mathrm{~cm}^{-1}$, using an alternating current.

\section{Results and discussion}

The effect of Se and Te on the sign of the temperature coefficient of electroconductivity $(\Delta \sigma / \Delta T)$ of metallic $\mathrm{Sb}$ and $\mathrm{Bi}$ was investigated.

System Sb-Se. The electroconductivity $(\sigma)$ of Sb melts with $0,4.0$ or 14.0 at.\% Se was measured at different temperatures. The results are given in Fig. 1.

As Fig. 1 shows, the electroconductivity of pure $\mathrm{Sb}$ melts and $\mathrm{Sb}$ melts with small Se additives is high (several thousands of $\mathrm{S} / \mathrm{cm}$ ) and has a negative temperature coefficient.

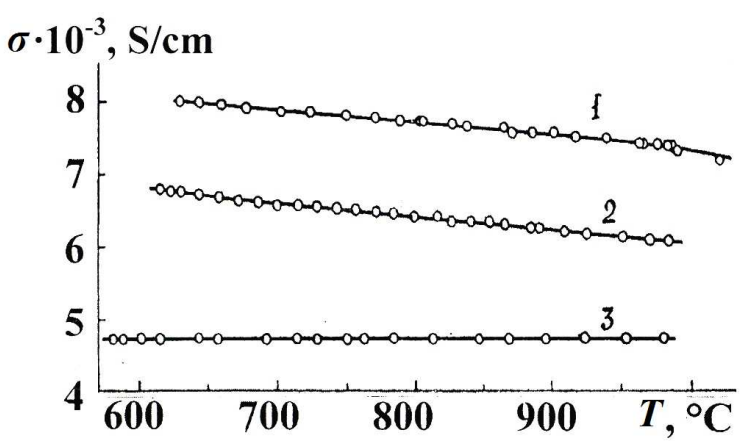

Fig. 1 Electroconductivity polytherms for Sb-Se melts: $1-0,2-4.0,3-14.0$ at.\% Se. 
Fig. 1 shows that the electroconductivity of composition 3 is independent of temperature $(\Delta \sigma / \Delta T=0)$. An increase of the Se content to more than 14 at.\% leads to inversion of the temperature coefficient.

System Sb-Te. The electroconductivity was investigated for melts with 9.6, 19.3, and 29.0 at.\% Te at different temperatures. The results are given in Table 1.

As shown in Table 1, $\sigma$ for pure antimony, and for the sample with 9.6 at.\% Te, decreases with increasing temperature. For the composition with 19.3 at.\% Te, a slow increase of the electroconductivity is observed at the beginning, and then, starting from $650^{\circ} \mathrm{C}, \sigma$ slowly decreases. Further increase of the $\mathrm{Te}$ content is accompanied by a change of the temperature coefficient from negative to positive, and the electroconductivity increases with increasing temperature.

System Bi-Se. The electroconductivity of $\mathrm{Bi}-\mathrm{Se}$ melts in the composition interval from 0 to 53.3 at.\% Se was investigated at different temperatures. The experimental results are given in Table 2.

The data in Table 2 show that increasing Se contents in molten $\mathrm{Bi}$ decrease the electroconductivity and change its character. The electroconductivity of the melts $1-4$ is characterized by a negative temperature coefficient. The absolute value of the coefficient becomes smaller with increasing $\mathrm{Se}$ content, and approaches zero for composition 4. For composition 5 , the sign of the temperature coefficient $\Delta \sigma / \Delta T$ becomes positive.

System Bi-Te. The electroconductivity of six melts containing from 0 to 60.03 at.\% Te was studied at different temperatures.

The experimental results are given in Fig. 2. The electroconductivity of melts of all the investigated compositions is high, reaching values of thousands of $\mathrm{S} / \mathrm{cm}$.

The electroconductivity of compositions 1,2 , and 3 decreases slightly with increasing temperature, and $\Delta \sigma / \Delta T$ is practically independent of temperature. The electroconductivity of compositions 4 and 5 has similar character: the polytherms show a concavity to the temperature axis. For composition 6 $(60.03$ at.\% Te) the electroconductivity has a positive temperature coefficient in the whole temperature interval.

Reciprocal peculiarities of the influence of the components on the electroconductivity are shown in Fig. 3, where $\sigma$ isotherms are drawn for the investigated systems.

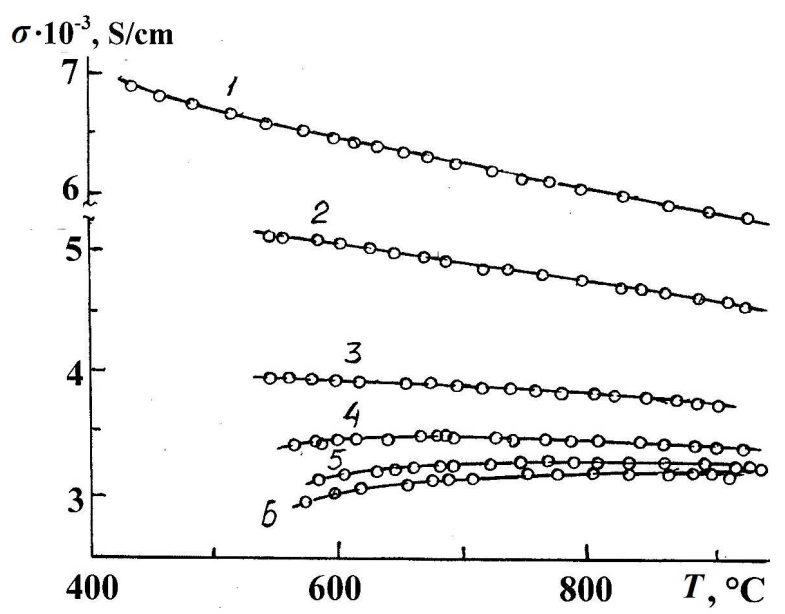

Fig. 2 Electroconductivity polytherms for Bi-Te melts: 1 - 0, 2 - 22.41, 3 - 41.71, $4-52.24,5-57.84,6-60.03$ at. $\%$ Te.

Table 1 Electroconductivity of molten samples in the system $\mathrm{Sb}-\mathrm{Te}$.

\begin{tabular}{|c|c|c|c|c|c|c|c|}
\hline \multicolumn{2}{|c|}{$\mathrm{Sb}$} & \multicolumn{2}{|c|}{9.6 at. $\% \mathrm{Te}$} & \multicolumn{2}{|c|}{19.3 at. $\%$ Te } & \multicolumn{2}{|c|}{29.0 at. $\% \mathrm{Te}$} \\
\hline$T,{ }^{\circ} \mathrm{C}$ & $\sigma, \mathrm{S} / \mathrm{cm}$ & $T,{ }^{\circ} \mathrm{C}$ & $\sigma, \mathrm{S} / \mathrm{cm}$ & $T,{ }^{\circ} \mathrm{C}$ & $\sigma, \mathrm{S} / \mathrm{cm}$ & $T,{ }^{\circ} \mathrm{C}$ & $\sigma, \mathrm{S} / \mathrm{cm}$ \\
\hline 1020 & 7204 & 983 & 5117 & 1022 & 4470 & 964 & 3932 \\
\hline 990 & 7313 & 952 & 5117 & 980 & 4470 & 924 & 3932 \\
\hline 983 & 7351 & 910 & 5154 & 952 & 4470 & 896 & 3932 \\
\hline 976 & 7427 & 868 & 5179 & 924 & 4518 & 868 & 3946 \\
\hline 963 & 7427 & 840 & 5243 & 896 & 4518 & 828 & 3969 \\
\hline 940 & 7504 & 798 & 5282 & 868 & 4566 & 805 & 3969 \\
\hline 902 & 7583 & 770 & 5309 & 816 & 4566 & 787 & 3969 \\
\hline 865 & 7664 & 728 & 5349 & 784 & 4616 & 757 & 3969 \\
\hline 827 & 7705 & 700 & 5376 & 757 & 4616 & 728 & 3969 \\
\hline 804 & 7746 & 675 & 5417 & 722 & 4616 & 700 & 3932 \\
\hline 771 & 7788 & 644 & 5445 & 700 & 4636 & 667 & 3896 \\
\hline 752 & 7830 & 613 & 5445 & 672 & 4636 & 644 & 3860 \\
\hline 703 & 7873 & 600 & 5473 & 644 & 4636 & 612 & 3791 \\
\hline 660 & 7960 & 594 & 5588 & 616 & 4616 & 560 & 3629 \\
\hline 630 & 8004 & 588 & 5588 & 567 & 4470 & 541 & 3539 \\
\hline
\end{tabular}


Table 2 Electroconductivity of molten samples in the system Bi-Se.

\begin{tabular}{c|c|c|c|c|c|c|c|c|c}
\hline \multicolumn{2}{c|}{$\mathrm{Bi}(1)$} & \multicolumn{2}{c|}{22.8 at.\% Se $(2)$} & \multicolumn{2}{c|}{38.9 at.\% Se (3) } & \multicolumn{2}{c|}{46.8 at.\% Se (4) } & \multicolumn{2}{c}{53.3 at.\% Se (5) } \\
\hline$T,{ }^{\circ} \mathrm{C}$ & $\sigma, \mathrm{S} / \mathrm{cm}$ & $T,{ }^{\circ} \mathrm{C}$ & $\sigma, \mathrm{S} / \mathrm{cm}$ & $T,{ }^{\circ} \mathrm{C}$ & $\sigma, \mathrm{S} / \mathrm{cm}$ & $T,{ }^{\circ} \mathrm{C}$ & $\sigma, \mathrm{S} / \mathrm{cm}$ & $T,{ }^{\circ} \mathrm{C}$ & $\sigma, \mathrm{S} / \mathrm{cm}$ \\
\hline 932 & 5768 & 1014 & 3937 & 1019 & 2893 & 1012 & 2370 & 1016 & 1942 \\
900 & 5820 & 1004 & 3832 & 1018 & 2888 & 1007 & 2370 & 983 & 1946 \\
871 & 5864 & 980 & 4025 & 1009 & 2892 & 992 & 2370 & 961 & 1963 \\
834 & 5935 & 961 & 4047 & 987 & 2905 & 980 & 2370 & 938 & 1958 \\
800 & 6020 & 937 & 4070 & 983 & 2905 & 948 & 2378 & 916 & 1947 \\
776 & 6076 & 902 & 4117 & 955 & 2928 & 921 & 2385 & 889 & 1936 \\
754 & 6089 & 885 & 4095 & 925 & 2940 & 888 & 2393 & 864 & 1921 \\
729 & 6159 & 850 & 4164 & 890 & 2965 & 858 & 2401 & 830 & 1901 \\
700 & 6220 & 819 & 4213 & 858 & 2989 & 832 & 2401 & 811 & 1896 \\
678 & 6280 & 784 & 4263 & 834 & 3001 & 809 & 2409 & 793 & 1886 \\
657 & 6318 & 752 & 4314 & 792 & 3014 & 780 & 2409 & 778 & 1876 \\
635 & 6366 & 729 & 4340 & 765 & 3040 & 753 & 2409 & 756 & 1857 \\
600 & 6440 & 698 & 4393 & 738 & 3053 & 731 & 2417 & 724 & 1842 \\
576 & 6500 & 670 & 4447 & 703 & 3079 & 710 & 2417 & 708 & 1828 \\
546 & 6573 & 644 & 4475 & 674 & 3092 & 683 & 2417 & 673 \\
519 & 6640 & 616 & 4531 & 647 & 3119 & 664 & 2417 & 658 & 1810 \\
488 & 6735 & 576 & 4618 & 627 & 3119 & 631 & 2417 & 630 & 1801 \\
462 & 6789 & 545 & 4678 & 599 & 3146 & 614 & 2417 & 628 & 1623 \\
438 & 6889 & 529 & 4709 & & & 599 & 2417 & 624 & 1566 \\
\hline
\end{tabular}

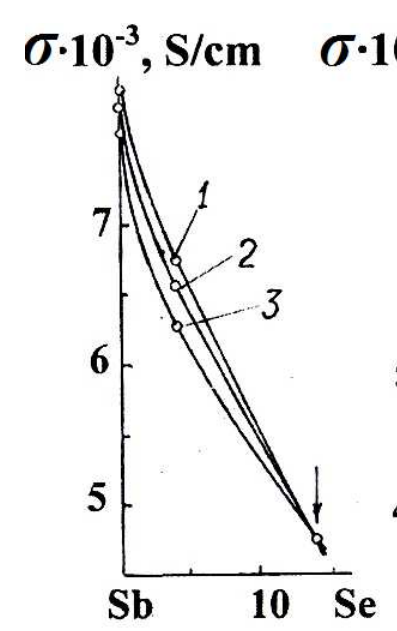

(a)

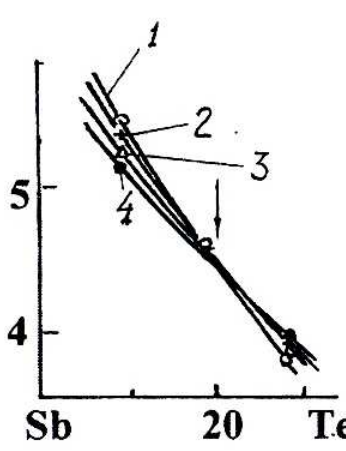

(b)

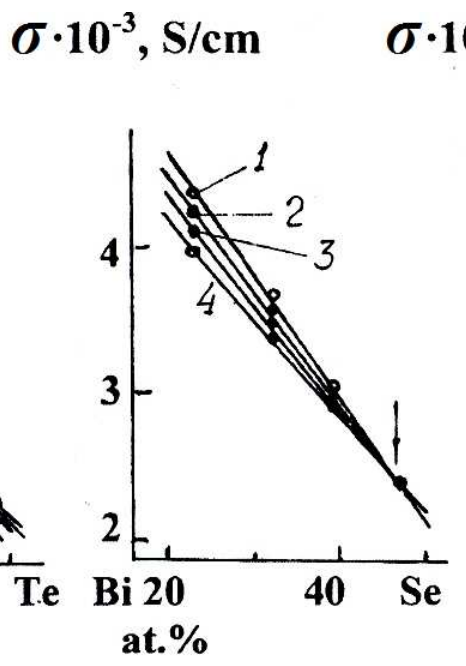

(c)

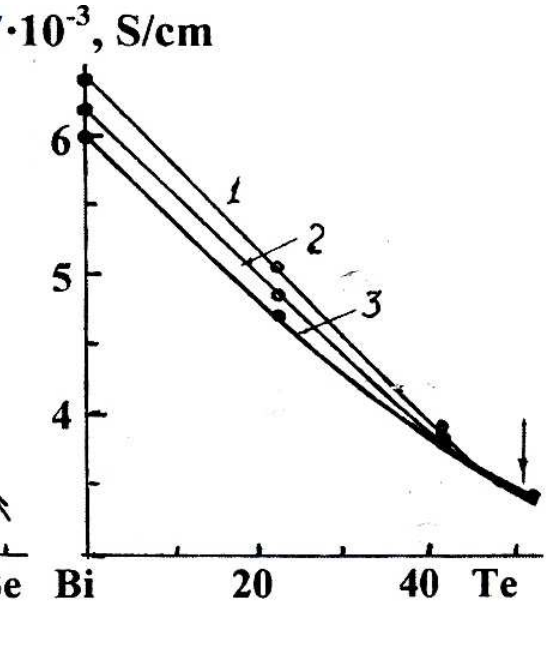

(d)

Fig. 3 Electroconductivity isotherms for molten samples in chalcogenide systems of antimony and bismuth; the arrows indicate the compositions at which sign inversion of the temperature coefficient takes place: (a) $1-650,2-750,3-850^{\circ} \mathrm{C}$; (b) $1-620,2-700,3-800,4-900^{\circ} \mathrm{C}$; (c) $1-710,2-800,3-900$, $4-1000^{\circ} \mathrm{C}$; (d) $1-580,2-700,3-800^{\circ} \mathrm{C}$.

As Fig. 3 shows, the electroconductivity falls with increasing chalcogen content in the antimony and bismuth melts. The temperature coefficient in the composition interval from the pure metal to the composition marked by a vertical arrow, has a negative sign.

Subsequent chalcogen adding (in the $\mathrm{Sb}-\mathrm{Se}$ system more than 14 at.\% Se; in Sb-Te > 19 at.\% Te; in $\mathrm{Bi}-\mathrm{Se}>47$ at.\% $\mathrm{Se}$; in $\mathrm{Bi}-\mathrm{Te}>51$ at.\% $\mathrm{Te}$ ) is accompanied by a sign inversion of $\Delta \sigma / \Delta T$ from negative to positive.

The changes of the values and the character of the conductivity in the investigated systems can be explained by chemical interaction of the components and the modification of the chemical bonds from metallic (for $\mathrm{Sb}$ and $\mathrm{Bi}$ ) to covalent, characteristic of the chalcogenides that form accordingly to the phase diagrams $[4,5]$. 


\section{Conclusions}

The composition dependence of the electroconductivity of melts was studied in the metalrich region of the systems $\mathrm{Sb}-\mathrm{Se}, \mathrm{Sb}-\mathrm{Te}, \mathrm{Bi}-\mathrm{Se}$, and $\mathrm{Bi}-\mathrm{Te}$. The compositions where the temperature coefficient of electroconductivity changes signs from negative to positive, were determined.

\section{References}

[1] V.F. Gillibrandt, G.E. Lendel, G.A. Brite, D.I. Gofman, Practical Guidance on Inorganic
Analysis, Goschimisdat, Moscow, 1957 (in Russian).

[2] V.A. Obolonchik, T.M. Mikhlina, Information Letter No.38, Institute for Problems of Materials Science, Kyiv, 1966.

[3] V.A. Obolonchik, V.G. Demianchuk, Information Letter No.39. Institute for Problems of Materials Science, Kyiv, 1966.

[4] M. Hansen, K. Anderko, Structure of Double Melts, Metalurgizdat, Moscow, 1962, 2 vols. (in Russian).

[5] N.H. Abrikosov, V.F. Bankina, L.V. Poretskaya, E.V. Skudnov, L.E. Shelimova, Semiconductor Compounds, Preparation and Properties, Nauka, Moscow, 1967 (in Russian).

Proceeding of the XV Scientific Conference "Lviv Chemical Readings - 2015",

Lviv, May 24-27, 2015 